\title{
Micro Grid Operation to Interface of Distributed Generation
}

\author{
M. Kiran Kumar \\ Dept. of Electrical and Electronics Engineering, Koneru lakshmaiah Education \\ Foundation, Green fields, Guntur District, Vaddeswaram, Andhra Pradesh 522502, \\ India \\ kiran.malligunta@gmail.com
}

\begin{abstract}
Distributed generations $(D G)$ are the ultra-modern mobile power resources which are located near the customer and generally used for small range of power requirements. The advantages of using embedded or local generation reserves are plenty which ensures power for all. The load along with local generation reserves and other auxillary units together is called microgrid. The energy management system involves in the proper balance with the parallel network which involves both local generation units along the traditional methods of power generation. The entire concept of local generation eliminates frequent conversion of $A C$ to DC between source and load. The power from renewable reserves is utilized for local load requirements. The novel power electronic technology-based converters are designed and used for interfaced the non-conventional energy centers with the gird for effective and dynamic load management. In gird coupled operation, the hybrid AC/DC microgrid is presented in this paper and extensive analysis is carried out with respect to feasibility of the proposed system in realtime. The renewable sources are solar power module, wind energy conversion system and battery for storage purpose. The simulation platform is MATLAB/SIMULINK environment and the results confirm the effectiveness of the proposed system.
\end{abstract}

Keywords: Microgrid, Non-conventional energy resources, Converters, Distributed generation, Power quality, Eco friendly energy production

\section{Introduction}

Embedded or distributed generation is installed locally to the load or remote customer side in order to meet the power consumption requirement which is generally small scale. The existing primitive methods of power generation are facing scarcity of working fuel and posing threat to the environment. The problems associated with transmission network will not be encountered if the embedded local generation is employed near the load center. The planning and incorporation of the embedded generation resources includes no compromise with respect to quality of power supplied to the consumers, no deviation in profile of the voltage waveform and significant enhancement of the network power transfer capability [1][2][3][4]. The power ratings of remote embedded generation units range from several kilowatts to higher order of megawatts. If the grid encountered with fault, the entire system operations in islanded mode, therefore causing no interruption in the power services delivered to the customer [5].The typical schematic arrangement of micro gird is diagrammatically elaborated in [Figure 1]. The general

Article history:

Received (June 22, 2019), Review Result (July 29, 2019), Accepted (September 18, 2019) 
rating of the embedded or distributed generation is typically 1MVA with the limited range of operation of 1 kilometer. The excess energy supplied is stored in form of batteries or flywheel. The microgrid often supplies both electricity and heat by means of combined heat and power plants (CHP) to the customers [6].

The advancement of microgrids can add to the lessening of outflows and the relief of atmosphere changes. From the client perspective, microgrids convey both warm and power prerequisites and what's more enhance neighborhood unwavering quality, diminish outflows, enhance control perfection by steady voltage and lessening voltage plunges and conceivably bring down expenses of vitality supply. This is because of the accessibility and creating advancements for conveyed units depend on inexhaustible sources and small scale sources that are described by low discharges [7].

Guaranteeing stable task amid arranging aggravations, keeping up security and power quality in the islanding method of activity requires the change of modern control procedures for microgrid's inverters with a specific end goal to give stable recurrence and voltage within the sight of self-assertively fluctuating burdens. Specialized difficulties connected with the task and controls of microgrids are colossal [7].

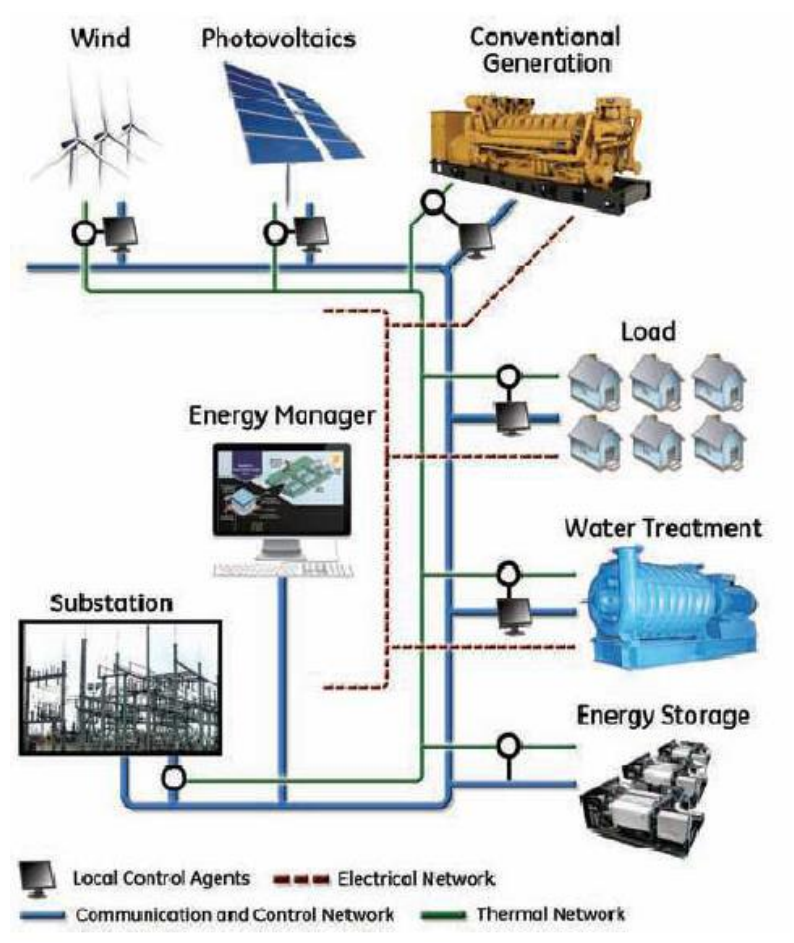

Figure 1. Schematic of typical micro gird

\section{System configuration}

The AC and DC joins are connected together through two transformers and two fourquadrant working three phase converters. The design of the mixture framework is appeared in [Figure 2] where different AC and DC sources and loads are associated with the relating AC and DC systems. The AC transport of the crossbreed framework is fixing to the utility network. 


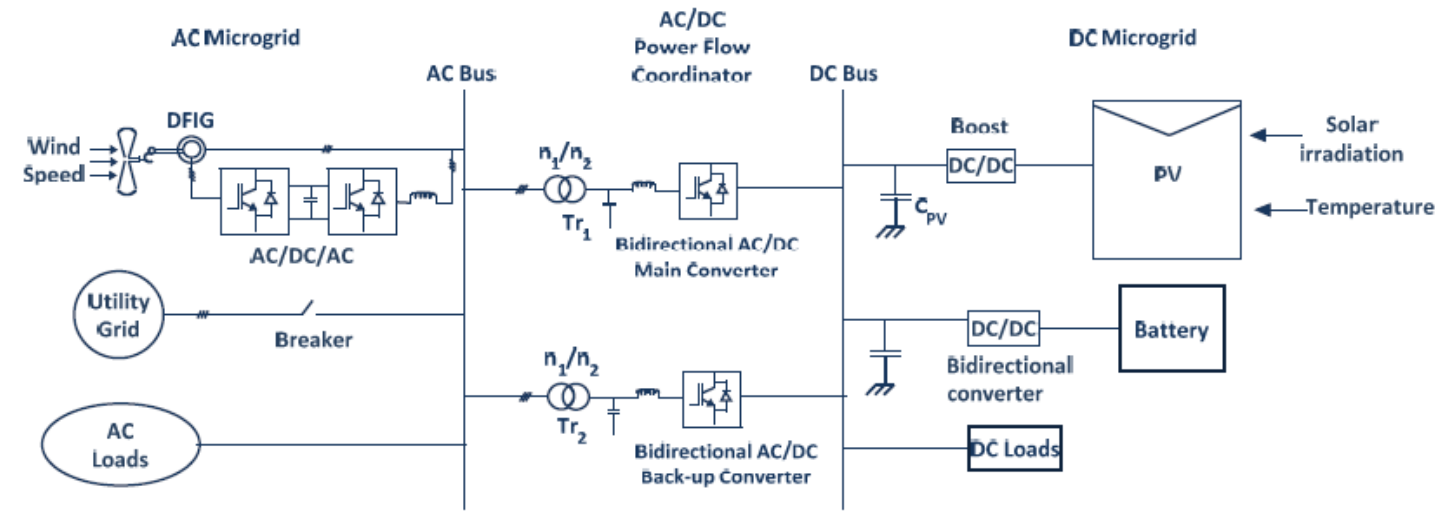

Figure 2. A hybrid AC/DC microgrid system

[Figure 3] depicts the half breed framework setup which comprises of AC and DC matrix. The AC transport is associated with the utility framework through a transformer and electrical switch. The AC and DC matrices have their comparing sources, burdens and vitality stockpiling components, and are interconnected by a three-stage converter.

In the proposed framework, PV clusters are associated with the DC transport through lift converter to reproduce DC sources. A DFIG wind age framework is associated with AC transport to mimic AC sources. A variable DC and AC load stack are associated with their DC and $\mathrm{AC}$ transports to reproduce different burdens. A battery with bidirectional DC/DC converter is associated with DC transport as vitality stockpiling.

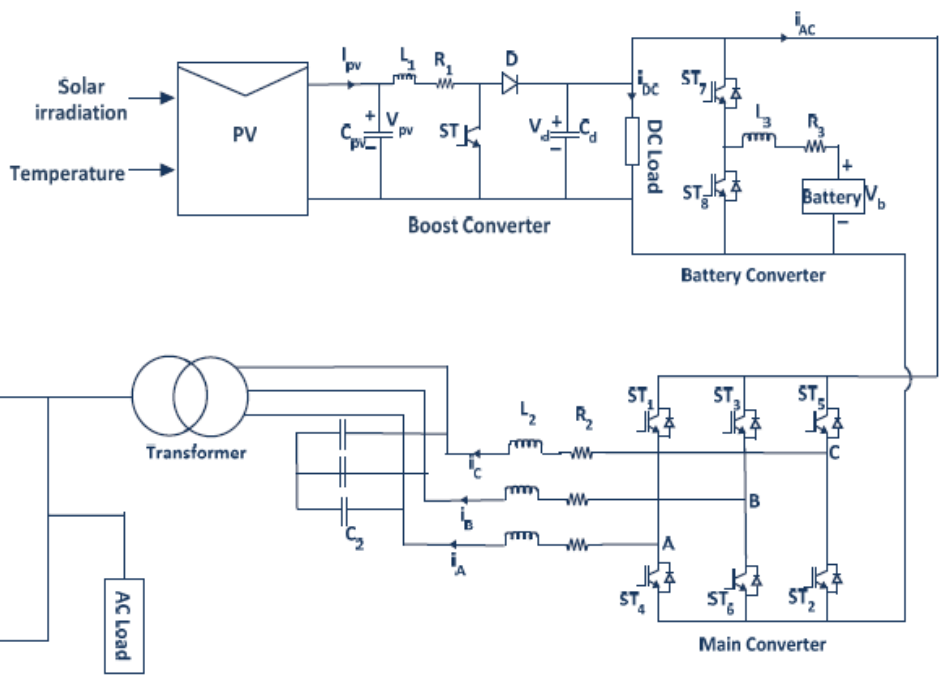

Figure 3. Hybrid system with three phase converters

PV modules are associated in arrangement and parallel. As sun based radiation level and surrounding temperature changes the yield energy of the sun oriented board modifies. A capacitor $\mathrm{Cpv}$ is added to the PV terminal with a specific end goal to smother high recurrence swells of the PV yield voltage. The three converters (support converter, primary converter, and bidirectional converter) share a typical DC transport. The bidirectional DC/DC converter is intended to keep up the steady DC transport voltage through charging or releasing the battery 
when the framework works in the self-ruling task mode. A wind energy production framework comprises of doubly encouraged acceptance generator (DFIG) with consecutive AC/DC/AC PWM converter associated between the rotor through slip rings and $\mathrm{AC}$ transport. The transformer ventures up the AC voltage of the fundamental converter to utility voltage level and to confine $\mathrm{AC}$ and $\mathrm{DC}$ matrices. The $\mathrm{AC}$ and DC transports are coupled through a threestage transformer and a fundamental bidirectional power stream converter to trade control amongst DC and AC sides.

\section{Results and discussion}

The activity is done for the gird framework associated mode. Alongside the novel microgrid connection scheme, the execution of the doubly encouraged induction generator, photovoltaic framework is simulated. The sun based light, cell temperature and wind speed are additionally contemplated for the investigation of novel microgrid connection scheme. [Figures 5] check that with increment of cell's working temperature, the present yield of PV module increments, though the maximum power yield lessens. Since the expansion in the yield current is significantly less than the decline in the voltage, the aggregate power diminishes at high temperatures.

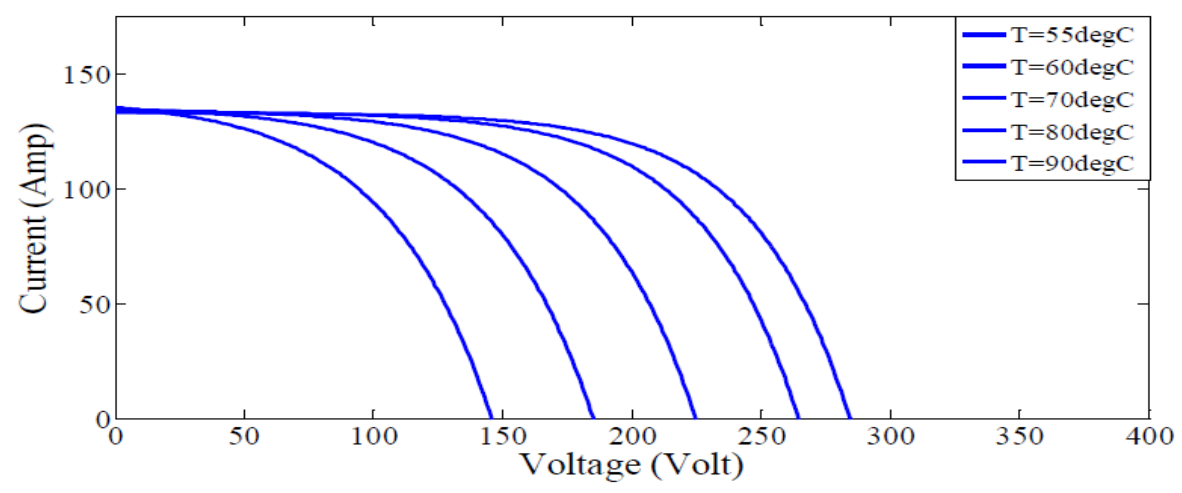

Figure 4. I-V array output characteristics for various temperatures

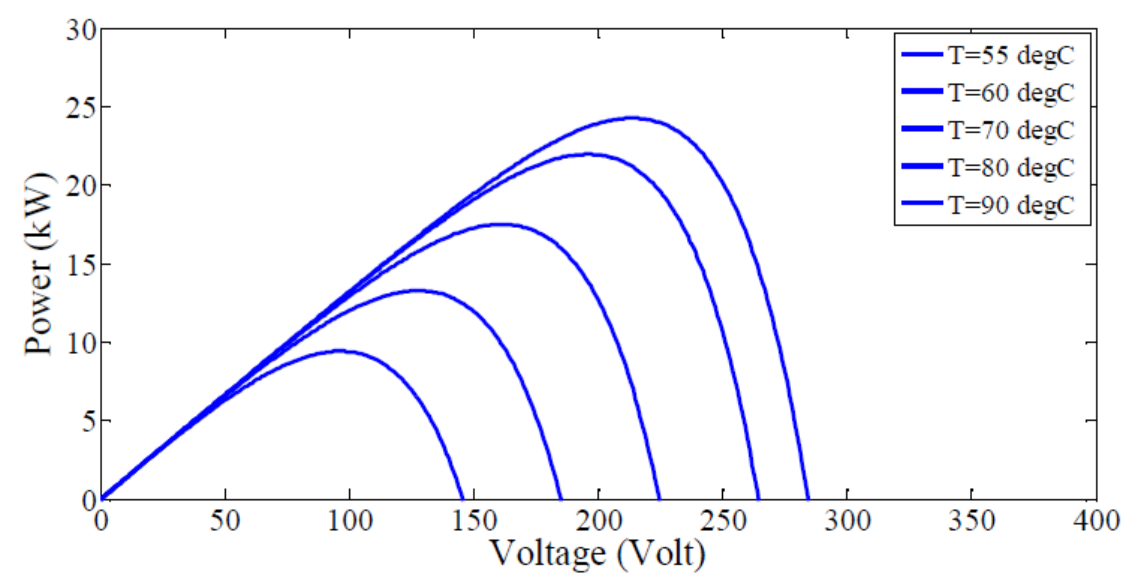

Figure 5. P-V array output characteristics at various temperatures 
The reaction of wind speed, three-stage stator voltage and three-stage rotor voltage are appeared in the [Figure 6] and [Figure 7]. Here the estimation of wind speed differs between 1.0 to $1.05 \mathrm{pu}$ which is important for the investigation of the execution of doubly sustained induction generator.

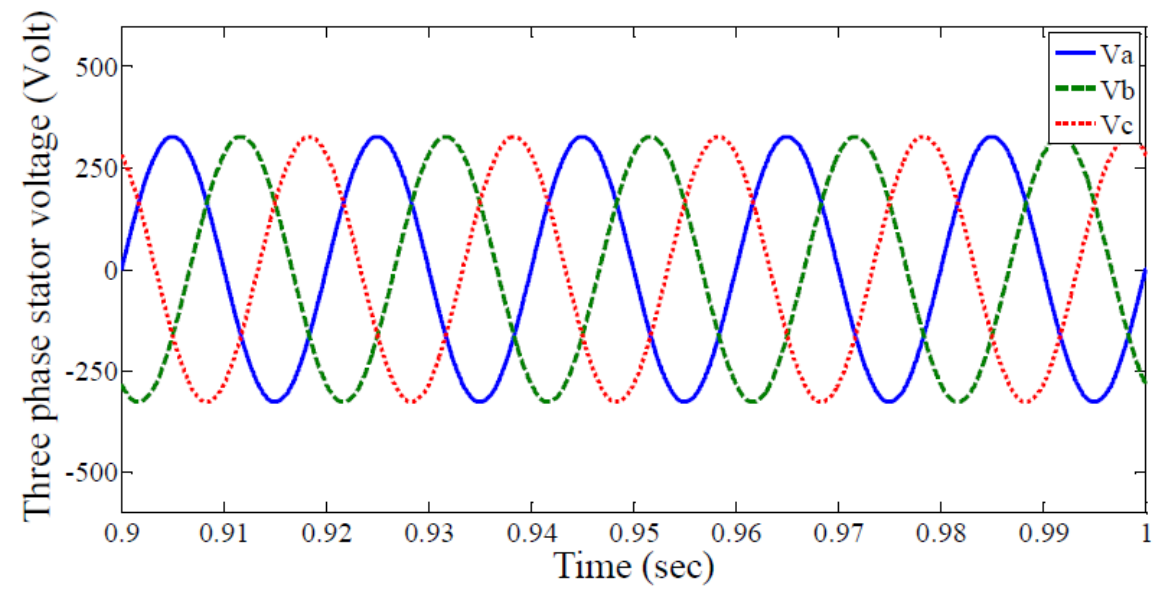

Figure 6. DFIG three phase stator voltages

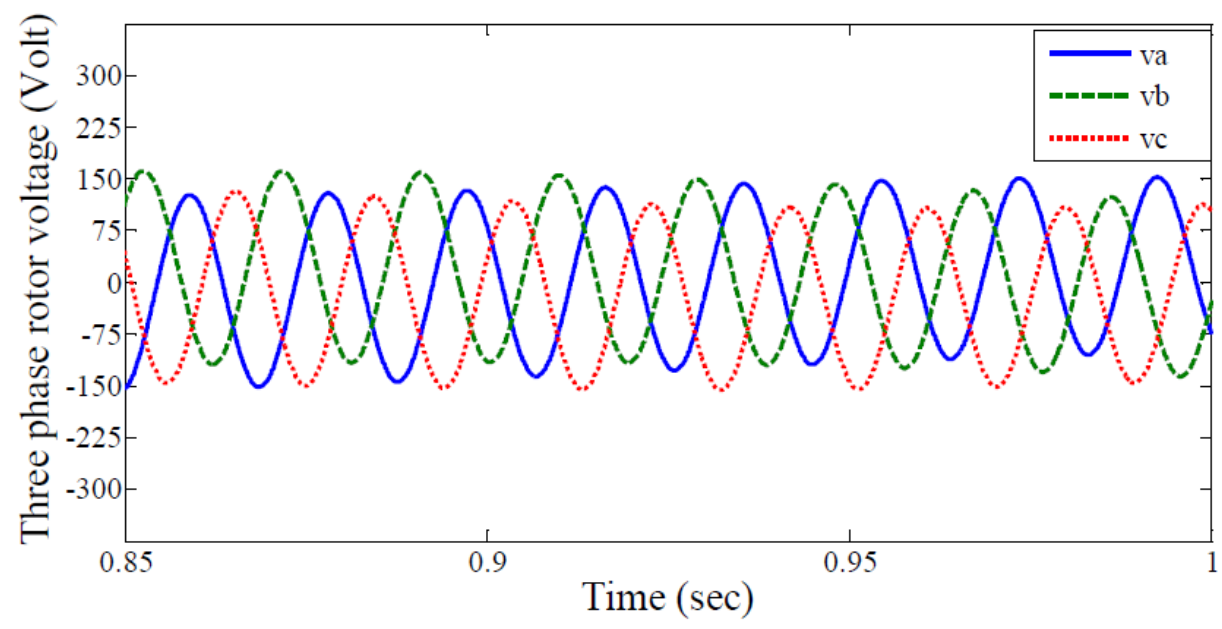

Figure 7. DFIG Three phase rotor voltages

\section{Conclusion}

The proposed framework is produced for the converters to keep up system stability under different burden or changing load conditions. MPPT calculation or algorithm is utilized to obtain the highest range of possible output power from DC sources and to facilitate the power transfer amongst DC and AC network. Despite the fact that the novel micro gird connection scheme can lessen the procedures of DC/AC and AC/DC transformations in an individual AC or DC network, there are numerous handy issues for the usage of the hybrid micro gird framework in view of the present AC overwhelmed foundation and framework. The productivity of the aggregate proposed micro gird framework relies upon the decrease of possible energy losses and the expansion for an additional DC connection. The crossbreed micro gird network can give a dependable, high caliber and more effective energy to the buyer. 
The proposed micro gird framework might be attainable for little confined modern plants with both PV frameworks and wind turbine generator as the future sole power supply.

\section{References}

[1] Smart Grid: An Introduction U.S. Department of Energy, (2009)

[2] E. M. Lightner and S. E. Widergren, “An orderly transition to a transformed electricity systems," IEEE Trans. Smart Grid, vol.1, no.1, pp.3-10, Jun, (2010) DOI: 10.1109/TSG.2010.2045013

[3] K. Moslehi and R. Kumar, “A reliability perspective of smart grid,” IEEE Trans. Smart Grid, vol.1, no.1, pp.5764, (2010) DOI: 10.1109/ISGT.2010.5434765

[4] G. T. Heydt, "The next generation of power distribution systems," IEEE Trans. Smart Grid, vol.1, no.3, pp.225235, (2010) DOI: 10.1109/TSG.2010.2080328

[5] A. Timbus, M. Liserre, R. Teodorescu, P. Rodriquez, and F. Blaabjerg, "Evaluation of current controllers for distributed power generation systems," IEEE Trans. Power Electron., vol.24, no.3, pp.654-664, (2009)

[6] R. H. Lasseter, “MicroGrids,” Proc. IEEE-PES'02, pp.305-308, (2002)

[7] F. D. Kanellos, A. I. Tsouchnikas, and N. D. Hatziargyriou, "Microgrid simulation during grid-connected and islanded mode of operation," Int. Conf. Power Systems Transients (IPST'05), June, (2005) 